\title{
Epidemiological, clinical and \\ economic burden of severe eosinophilic asthma in Taiwan: Results from a large tertiary care hospital
}

\author{
Sumitra Shantakumar, ${ }^{1}$ Yu-Fan Ho, ${ }^{1}$ Li-Wen Tuan, ${ }^{2}$ Tzu-Mei Lin, ${ }^{3}$ Yi-Hsing Chen, ${ }^{3}$
}

\begin{abstract}
Background: Burden of severe eosinophilic asthma (SEA) data in Asia are limited.

Objective: This retrospective, observational study characterized SEA epidemiology, healthcare resource use (HCRU) and costs for adult patients in Taiwan.

Methods: Data from Taichung Veterans General Hospital electronic medical record database, between 2013 to 2016 , were extracted. Eligible general asthma patients were $\geq 18$ years at index date, with $\geq 1$ medical claim with an asthma diagnosis after the index date. Patients with SEA (meeting additional criteria: Global Initiative for Asthma Step 4/5 treatment guidelines [within 3 months preceding index date], $\geq 2$ clinically significant exacerbations, and eosinophil counts $\geq 300$ cells $/ \mu \mathrm{L}$ [within 12 months preceding index date] or $\geq 150$ cells $/ \mu \mathrm{L}$ [on index date]) and SEA patients using high-dose inhaled corticosteroids (HD ICS) were also identified. Twelve months' pre-index data were used to evaluate exacerbation frequency, treatment patterns, HCRU, and costs (2016 US Dollars).
\end{abstract}

Results: Of 2,601 eligible general asthmatic patients, 162 (6.2\%) met predefined criteria for SEA; of SEA patients, 72/162 (44.4\%) had used HD ICS. SEA and HD ICS SEA patients experienced more clinically significant exacerbations than general asthma patients $(1.6 \pm 3.3$ and $1.5 \pm 2.6$ vs $0.6 \pm 2.0, p<0.01)$. HD ICS SEA and SEA patients incurred at least 2-2.5-fold higher total asthma-related and all-cause costs than general asthma patients and had significantly greater HCRU.

Conclusions: Of eligible Taiwanese general asthma patients, $6.2 \%$ met predefined SEA criteria. Compared with general asthma patients, SEA and HD ICS SEA patients used more respiratory medications, experienced more exacerbations, and incurred greater HCRU and higher costs.

Key words: severe eosinophilic asthma, high-dose inhaled corticosteroids, Taiwan, epidemiology, health care costs

From:

${ }^{1}$ Department of Epidemiology, GlaxoSmithKline,

GSK Asia House, Singapore

Formosa Biomedical Technology Corp. CRO Division, Taipei, Taiwan

Taichung Veterans General Hospital, Taichung, Taiwan

\section{Introduction}

Most asthma cases are controlled with available medication or stepped up if they remain uncontrolled. For patients with Severe Asthma (SA), however, most still have poor asthma control, persistent airflow limitation, and frequent severe exacerbations. ${ }^{1,2}$

Estimates, predominantly from Western countries, indicate low prevalence of SA (5-10\%), ${ }^{1}$ however, this group contributes to disproportionally high health-care resource use
Corresponding author:

Yi-Hsing Chen

Chief of the Division of Allergy, Immunology and Rheumatology at Taichung Veterans General Hospital, Taichung, Taiwan

E-mail: dr.yihsing@gmail.com
(HCRU, $~ 50 \%$ ) due to treatment of frequent acute exacerbations. ${ }^{3}$ Compared with controlled asthma, uncontrolled disease imposes substantial direct and indirect costs through lost working days, ${ }^{4}$ increased total and asthma-related healthcare costs, ${ }^{5,6}$ decreased health-related quality of life, ${ }^{7,8}$ and increased risk of death. ${ }^{9}$ As current therapies do not adequately control symptoms for all patients with SA, there is an unmet need for therapeutic options to reduce SA-related morbidity and mortality. 
Severe eosinophilic asthma (SEA), associated with elevated blood and sputum eosinophil counts, ${ }^{1,10,11}$ and severe allergic (immunoglobulin [Ig]E-mediated) asthma (SAA), are SA phenotypes that can overlap leading to overlap in treatment eligibility. ${ }^{12}$ Clinical characterization of SEA patients, and examination of their associated HCRU, has been conducted in Western countries but are poorly described in Asia. This study aimed to characterize the epidemiology and clinical characteristics of adult patients with SEA in Taiwan, to describe dispensed medications, HCRU and associated asthma-related and all-cause costs.

\section{Methods \\ Objectives}

To estimate the prevalence of asthmatic patients in Taiwan meeting SEA criteria, describe patient demographics, clinical characteristics, respiratory medication use, and quantify HCRU and costs (all-cause and asthma-related) over 12-months.

\section{Study design}

This retrospective population study utilized data from July $1^{\text {st }}, 2013$ through June $30^{\text {th }}, 2016$, obtained from the Taichung Veterans General Hospital (VGHTC) electronic medical record (EMR) database (see Appendix S1). The VGHTC is a large tertiary center with up to 190 million outpatient visits annually and a high proportion of returning patients. Exacerbation frequency, treatment patterns and HCRU/costs were assessed post-index period (index was defined as the date with the first confirmed diagnosis of asthma after July $1^{\text {st }}$, 2014; Figure S1).

\section{Patient Cohort Identification}

Included patients were: $\geq 18$ years at index date, with a record of $\geq 1$ medical claim with an asthma diagnosis (International Classification of Diseases-9: 493.xx; -10: J45 or J46, see Appendix S1) after July $1^{\text {st }}, 2014$, minimum of 12 months' medical data available before (baseline) and after (follow-up) the index date for a total of 24 months. Patients with chronic obstructive pulmonary disease (COPD) and smokers were not excluded (see Appendix S1).

Patients were further classified as having SEA if they: met the criteria for GINA Step 4 or 5 treatment guidelines ${ }^{13}$ in the 3 months prior to index date, had $\geq 2$ clinically significant exacerbations in the 12 months prior to index date, and had $\geq 1$ blood eosinophil count (BEC) result of $\geq 300$ cells/ $\mu \mathrm{L}$ (steady state or exacerbated state) in the 12 months prior to index date, $\mathrm{OR} \geq 150$ cells $/ \mu \mathrm{L}$ measured on index date. Patients meeting SEA criteria were stratified by the following BEC ranges: $<150,150-300,>300-400$, and $>400$ cells $/ \mu \mathrm{L}$. As there is currently no gold standard for defining eosinophilic asthma severity, ${ }^{14}$ different cut-offs were explored to define SEA and to determine the corresponding effect on the prevalence.

A subset of SEA population who had ever been treated with HD ICS was also extracted and analyzed.

Patients meeting the SEA criteria were additionally classified based on the number of exacerbations and their use of oral corticosteroid (OCS).

\section{Study procedures and evaluations}

See Appendix S1 for further details.

\section{Demographics and clinical characteristics}

These were described for patients at study index date.

\section{Exacerbations}

Clinically significant asthma exacerbations were recorded during the 12-month follow-up period (inclusive of index date) and were defined as an asthma-related ED visitor hospital admission, or an exacerbation treated with OCS.

\section{Asthma medication}

Asthma medication exposure, including pattern of medication use, adherence, and OCS average daily dose, were defined as:

Medication use: The distribution of patients prescribed $\geq 1$ asthma medications over the 12-month index period were summarized.

Medication adherence: Adherence to controller therapy at index date was assessed over 365 days using proportion of days covered (PDC).

OCS average daily dose: The average daily dose for OCS was described for OCS episodes (defined as a sequence of OCS claims that occurred $\leq 7$ days apart.

\section{Healthcare resource use}

Asthma-related HCRU data (encompassing medical claims with an asthma diagnosis in the primary position) were examined during the 12-month follow-up period (inclusive of index date). Frequency of out-patient department (OPD) visits, ED visits, hospitalizations ( $\geq 1$ day to distinguish from patients who received diagnostic services or procedures), average length of stay, and intensive care unit (ICU) admission (Yes/No) were analyzed.

\section{All-cause and asthma-related healthcare costs}

Healthcare costs comprised all medical fees (medication, examination, surgeries, inpatient hospital admissions, OPD, ER, wards, etc.) charged to the patient.

\section{Statistical analysis}

For medication adherence, PDC was multiplied by 100 to yield a percentage and categorized as high ( $>80 \%)$, medium $(80 \% \geq \mathrm{PDC} \geq 50 \%)$, low $(50 \%>\mathrm{PDC} \geq 30 \%)$, and very low $(<30 \%)$ based on published literature..$^{15,16}$

For HCRU, frequency rates (number of events/person/ year) were evaluated. For economic endpoints, asthma-related healthcare costs paid to providers were computed per patient annually and applied to costs of hospitalization, OPD visits, and ED visits. Costs were standardized and reported in 2016 US dollars using the Medical Care Consumer Price Index. A non-parametric bootstrap procedure was used to carry out statistical inference and determine $p$-values for the cost difference between exposure groups (see Appendix S1 for bootstrapping algorithm). 
Economic outcomes, demographics and clinical characteristics were summarized by descriptive statistics ( $\mathrm{n}$ and mean \pm standard deviation (SD) for continuous parameters, and frequency and percentage for categorical parameters).

Statistical analyses were performed for SEA, and HD ICS SEA, vs general asthma populations; $p<0.05$ was considered statistically significant. Continuous variables were analyzed using $t$-test and categorical variables using Chi-square test. All analyses were conducted using SAS version 9.4. This was a descriptive epidemiologic study therefore no controlling for confounding, sample size or power/precision calculations were performed. Missing values were not imputed. Data cleaning methods were not required.

\section{Ethics Approval and Consent to Participate}

This observational study complied with the principles laid down by the $64^{\text {th }}$ World Medical Assembly (Helsinki, 2013). The study was conducted in accordance with legal and regulatory requirements/guidelines, as well as with scientific purpose, value and rigor; and followed generally accepted research practices.

Informed consent was not required in this retrospective study using the VGHTC database since these anonymized data were approved for the use in observational research and the study did not involve the contact with patients. This study complied with all applicable laws regarding subject privacy. The study posed minimal privacy risk for patients and had been approved by the Institutional Review Board of VGHTC (IRB code: SF16245B).

\section{Results}

\section{Baseline patient demographics and clinical characteristics}

Of 9,455 patients with asthma diagnosis codes, 2,601/9,455 (27.5\%) met the inclusion criteria; 162/2,601 (6.2\%) met SEA criteria and among these, $72 / 162$ patients (44.4\%) had used HD ICS (Figure 1). Mean age was comparable between the populations, and most patients were aged $\geq 50$ years. SEA and general asthma patients had comparable BMI scores, while HD ICS SEA patients had a significantly higher BMI compared with general asthma patients $(p<0.05)$. Most patients from all populations had total IgE levels of $>30$ and $<1300$ IU/mL (Table 1).

A significantly greater proportion of HD ICS SEA and SEA patients were female compared with general asthma patients $(56.9 \%$ and $51.9 \%$, respectively vs $40.8 \%$; $p<0.01$ ), had atopy and had more comorbidities; HD ICS SEA and SEA populations also included higher proportions of patients who were current or had ever been smokers. On the index date, BECs of $\geq 300$ cells $/ \mu \mathrm{L}$ were recorded for $58.0 \%$ of SEA patients vs $52.7 \%$ HD ICS SEA patients vs $14.7 \%$ general asthma patients (Table 1). Findings for the BEC subgroups of SEA patients are reported in Appendix S2.

\section{Exacerbations}

In the 12-month follow-up period, the mean number of exacerbations was significantly higher for HD ICS SEA and SEA vs general asthma patients: $1.5 \pm 2.59$ and $1.6 \pm 3.32$ vs $0.6 \pm 2.02$, respectively (Table 2 ).
9,455 asthma patients identified in the VGHTC database

from July $1^{\text {st }}, 2014$ to June $30^{\text {th }}, 2016$

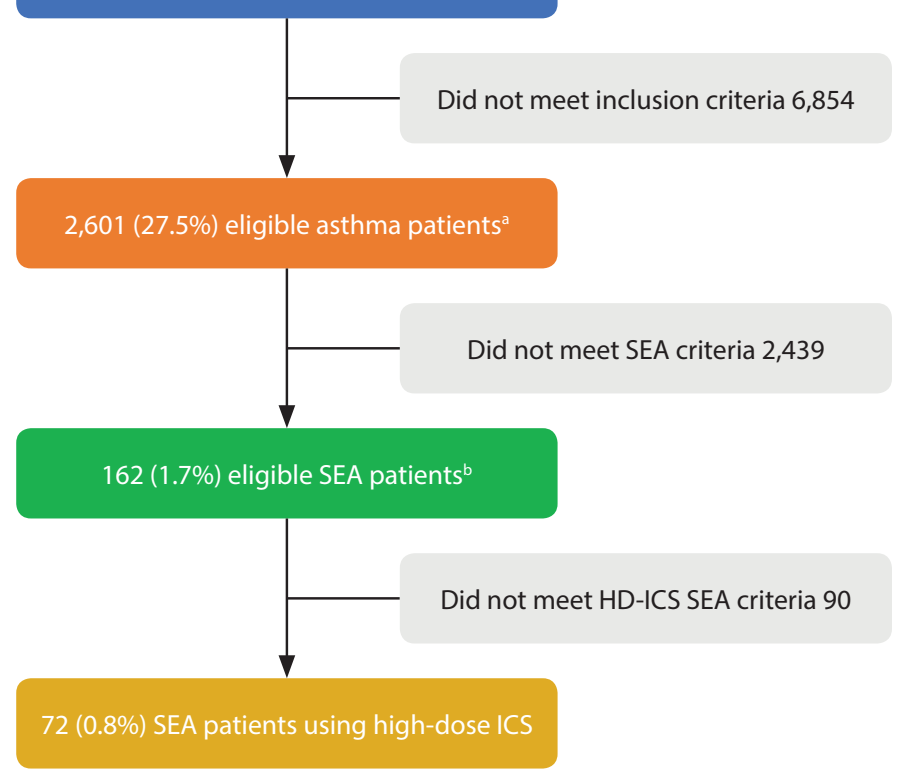

Figure 1. Patient flow diagram

${ }^{a}$ asthma patients meeting criteria $1-3$; ${ }^{\text {b }}$ SEA patients meeting criteria $1-6$; ICS, inhaled corticosteroids; SEA, severe eosinophilic asthma; VGHTC, Taichung Veterans General Hospital.

Proportions of SEA and HD ICS SEA patients experiencing 1-2, 3, or $\geq 4$ exacerbations were at least 2-fold greater compared with general asthma patients $(p<0.0001$; Table 2). Proportions of patients who experienced exacerbations requiring hospitalization or an $\mathrm{ED}$ visit were highest for $\mathrm{HD}$ ICS SEA patients, while those who used OCS was highest for the general asthma population (Table 2).

\section{Utilization of respiratory medications}

The respiratory medications coverage rate in the 12-month follow-up period was significantly higher for HD ICS SEA and SEA vs general asthma patients, with 2- to 3-fold greater use for many medication classes, including LAMA, SABA, theophylline and tiotropium (Table 3). Overall, a fixed-dose ICS + LABA combination was the most commonly used medication, and was used by all HD ICS SEA, 94.4\% of SEA vs $57.6 \%$ of general asthma patients (Table 3 ).

In the SEA and HD ICS SEA populations, proportions of patients receiving omalizumab was low, but significantly greater than for general asthma patients $(6.2 \%$ and $9.7 \%$ vs $2.3 \%$, respectively). At least 2 -fold more SEA and HD ICS SEA patients than general asthma patients used systemic corticosteroids ( $14.8 \%$ vs $16.7 \%$ vs $6.4 \%$, respectively, Table 3 ).

When classified based on exacerbations and OCS use, the number of SEA patients with 6 months' continuous use of OCS was low across subpopulations (see Appendix S2). 


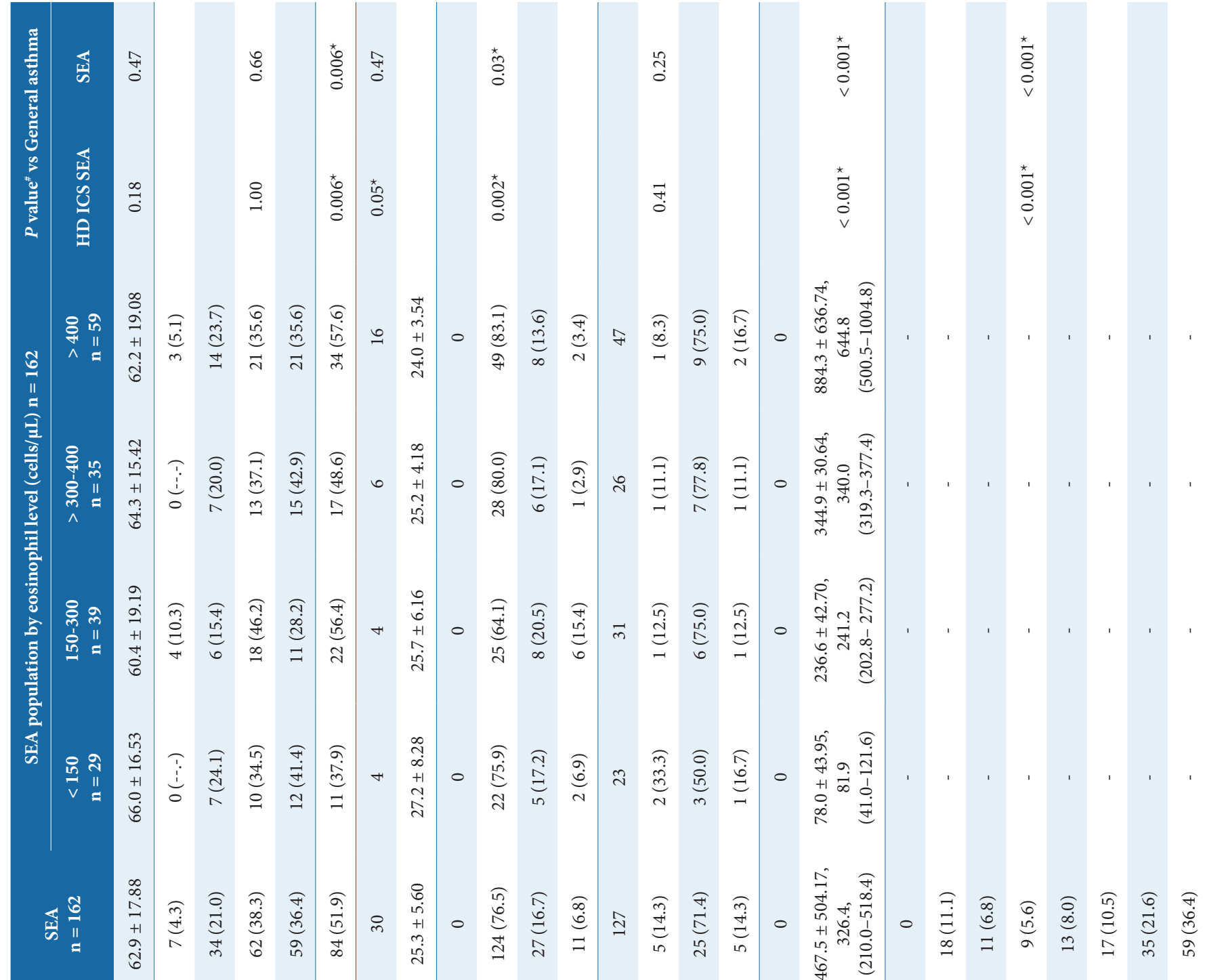



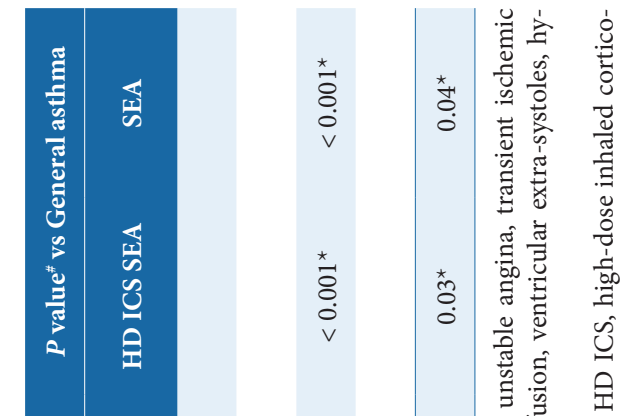

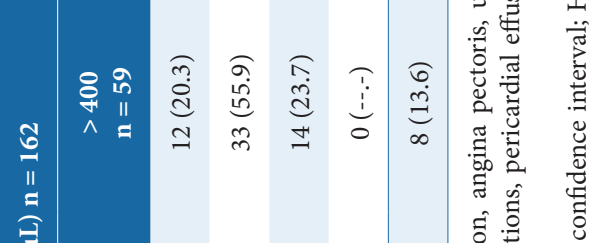
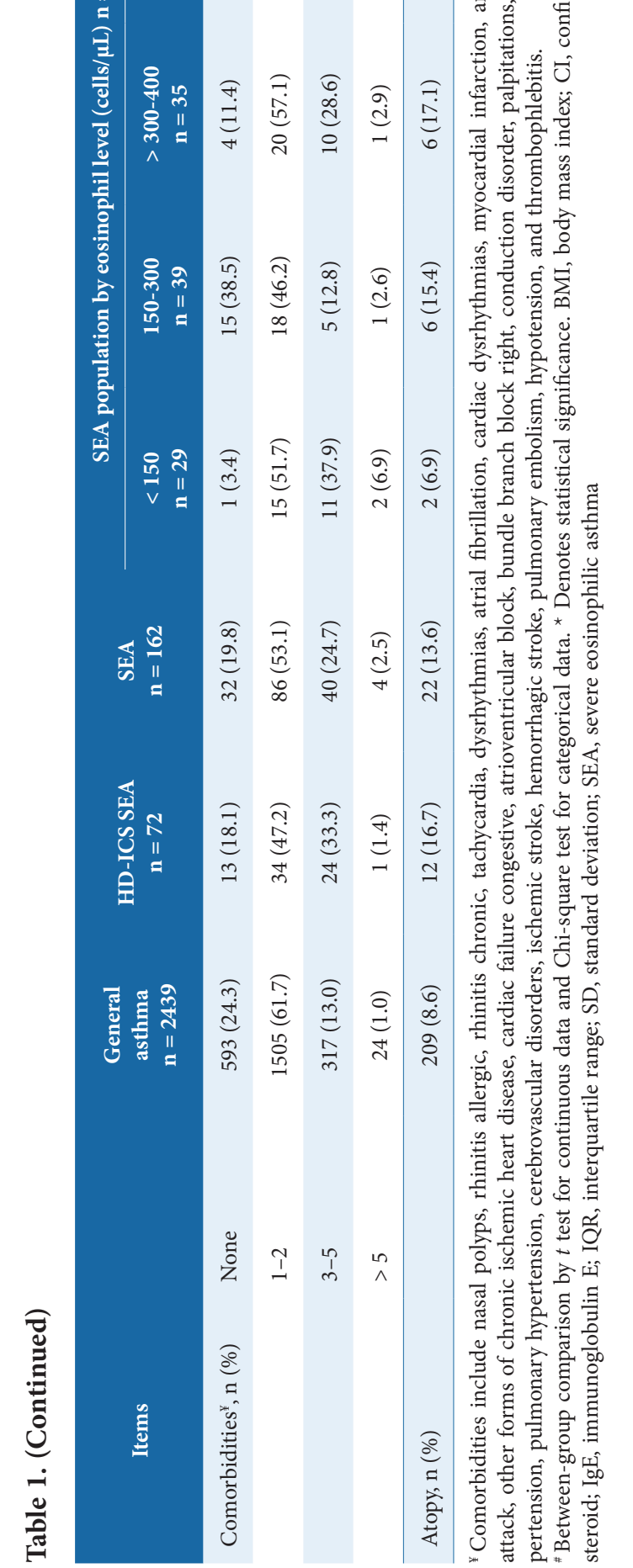

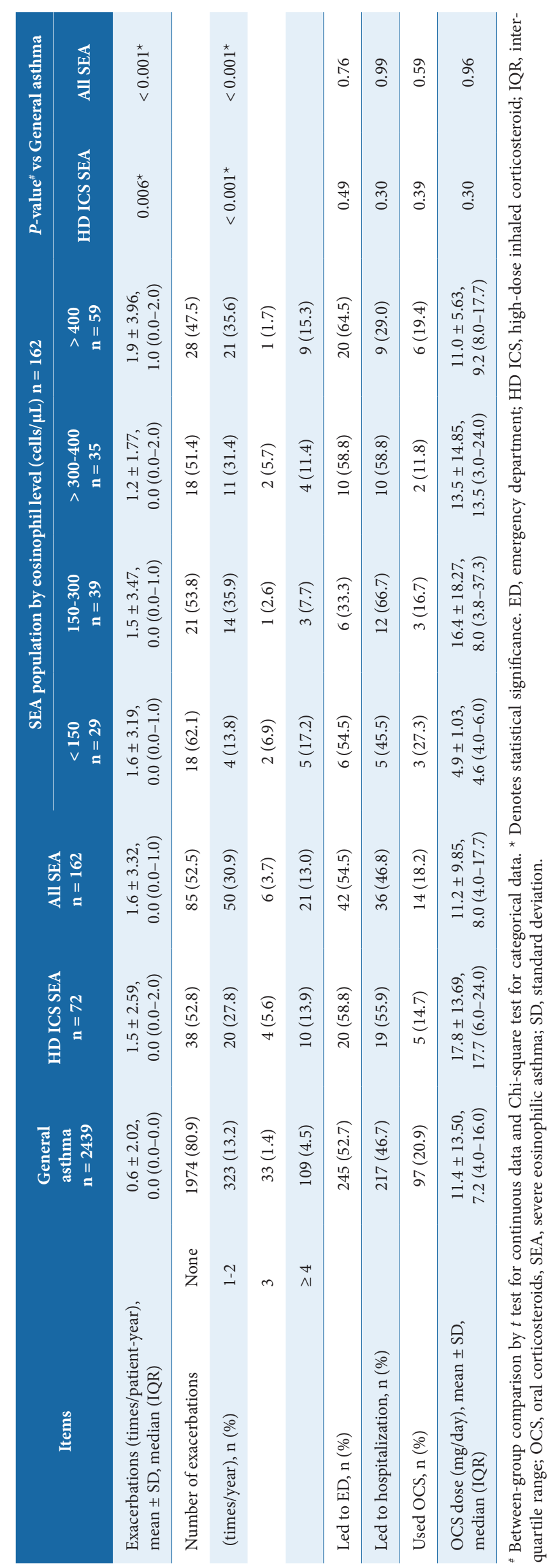




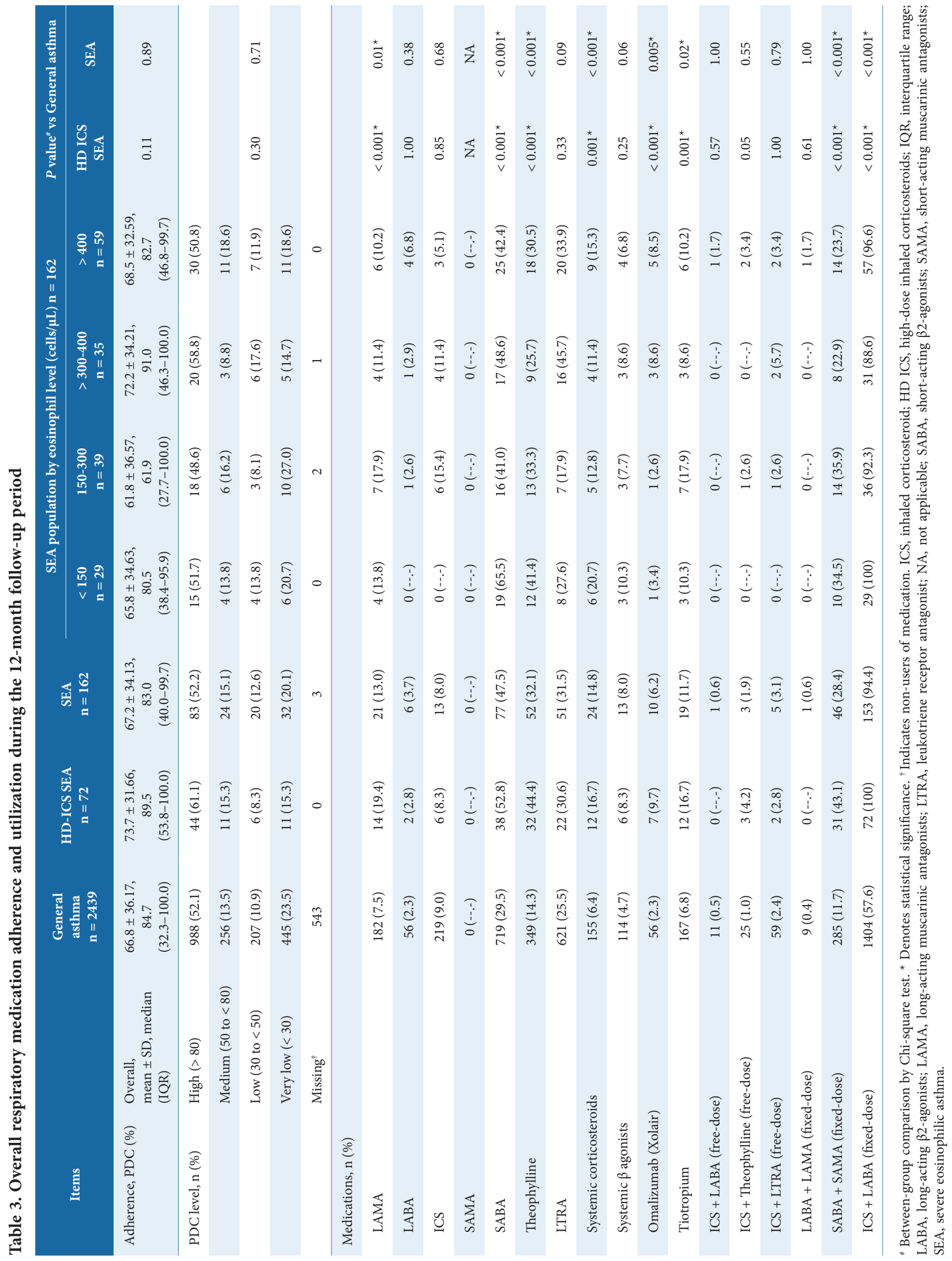




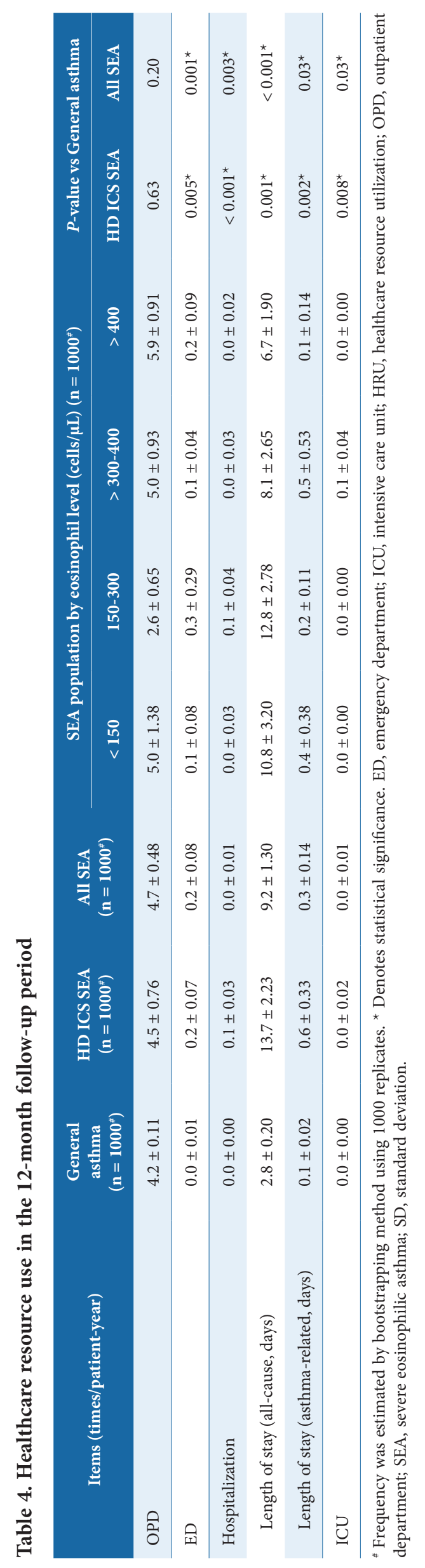


A. Asthma-related medical costs in the 12-month follow-up period

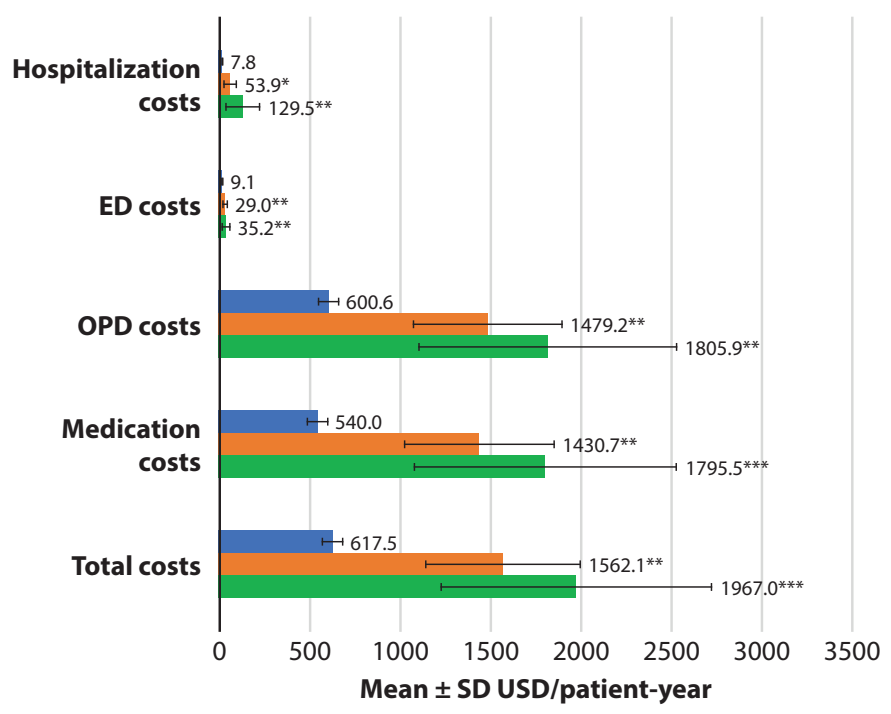

General asthma SEA HD-ICS SEA

\section{All-cause medical costs in the 12-month follow-up} period

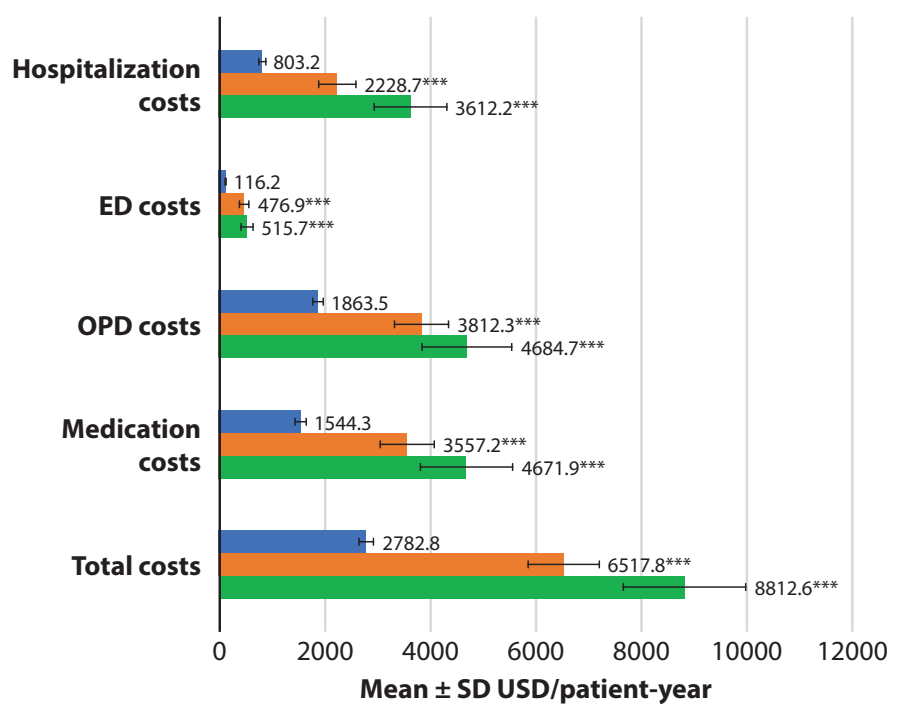

$\begin{array}{lll}\text { General asthma } & \text { SEA HD-ICS SEA }\end{array}$
B. Asthma-related medical costs in the $\mathbf{1 2}$ month follow up period for the SEA population stratified by eosinophil level

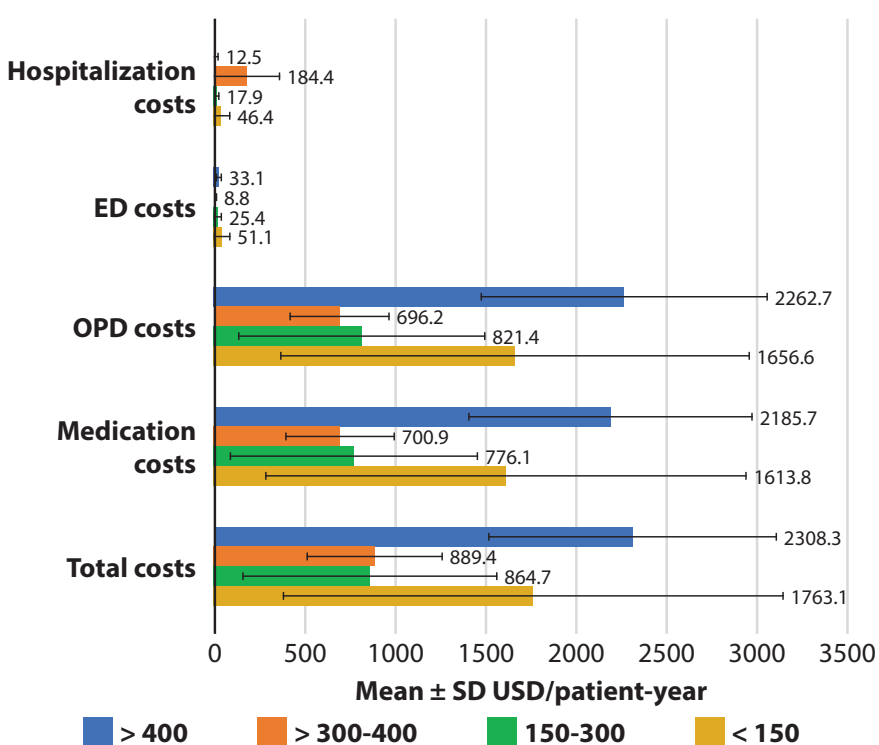

D. All-cause medical costs in the $\mathbf{1 2}$ month follow up period for the SEA population stratified by eosinophil level

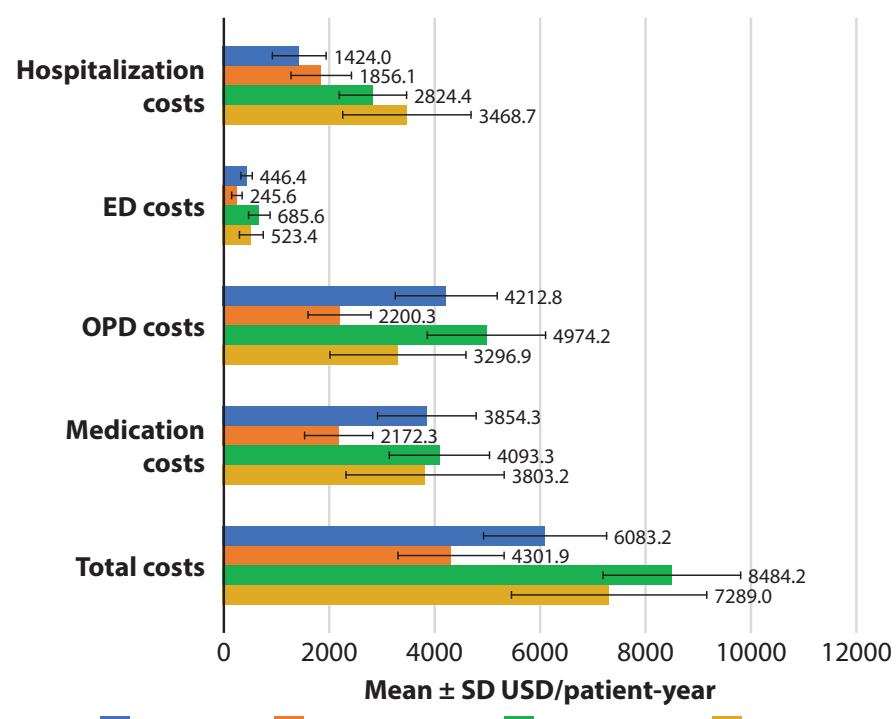

$>400$

$150-300$

$<150$

Figure 2. Asthma-related and all-cause medical costs in the 12-month follow-up period

A. Asthma-related costs in HD ICS SEA, SEA and general asthma populations

B. Asthma-related costs in SEA population stratified by eosinophil level

C. All-cause medical costs in HD ICS SEA, SEA and general asthma populations

D. All-cause medical costs in SEA population stratified by eosinophil level

Costs were estimated by bootstrapping method using 1000 replicates. ${ }^{*} p$ value $<0.05,{ }^{* *}<0.01$ and ${ }^{* *}<0.001$. ED, emergency department; HD ICS, high-dose inhaled corticosteroids; OPD, outpatient department; SD, standard deviation; SEA, severe eosinophilic asthma; USD, United States Dollars 


\section{Adherence to respiratory medications}

Mean overall PDC, for aggregated respiratory medications, and for most specific medications, was comparable between SEA and general asthma patients and higher for HD ICS SEA patients in the 12-month follow up period (Table 3). The greatest proportion of patients with a PDC level $\geq 80 \%$, was observed in HD ICS SEA patients (HD ICS SEA vs SEA vs general asthma: $61.1 \%$ vs $52.2 \%$ vs $52.1 \%$; Table 3 ).

\section{Healthcare resource use and costs}

There were significantly more asthma-related ED visits, but not OPD visits, for both SEA and HD ICS SEA populations vs the general asthma population in the 12-month follow up period $(p<0.01)$. SEA and HD ICS SEA patients also had significantly higher asthma-related hospitalizations and ICU admissions. Asthma-related length of stay, and all-cause length of stay was significantly longer by at least 3-fold for these patients vs general asthma patients $(p<0.05$; Table 4$)$.

\section{Asthma-related and all-cause costs}

The HD ICS SEA and SEA populations incurred significantly greater asthma-related costs for each healthcare category vs the general asthma population; total asthma-related costs were also higher by at least 2.5 -fold for these patient populations. OPD costs were the primary driver of total costs (Figure 2A). Significantly greater all-cause costs (2-3 fold) across all healthcare categories were also incurred by HD ICS SEA and SEA populations vs the general asthma population; total all-cause costs were $\$ 8812.6$ and $\$ 6517.8$ vs $\$ 2782.8$, respectively. OPD costs were the primary driver of total costs (Figure 2C).

There was variation in HCRU and costs between the BEC subgroups of SEA patients (Appendix S2).

\section{Discussion}

Real-world evidence describing patients with SEA and their associated HCRU is limited in Asia. We found 6.2\% of patients met predefined criteria for SEA; $44.4 \%$ of these had used HD ICS therapy. SEA and HD ICS SEA patients experienced a higher number of exacerbations than general asthma patients despite greater medication usage, and accounted for higher asthma-related and all-cause HCRU and costs.

HD ICS SEA and SEA patients in Taiwan were similar in age to general asthma patients and more likely to be female, contrasting with a UK SEA population who were more likely to be older than the main study population and for which similar proportions of female patients were found. ${ }^{17}$ In the SA Research Program however, female patients were also more likely to have SEA. ${ }^{18}$ Consistent with the UK study, Taiwanese SEA and HD ICS SEA patients had more comorbidities and atopy. ${ }^{17}$

Epidemiological and HCRU data on SEA patients is available from Western studies. Kerkhof et al (2018) reported that $10 \%$ of UK patients with active asthma were prescribed HD ICS/LABA - greater than the proportion we identified. Patients with SEA (defined similarly to our study as $\geq 2$ exacerbations in the baseline year and a BEC of $\geq 0.3 \times 10^{9} / \mathrm{L}$ at index date; $\mathrm{n}=2940,0.8 \%$ ) also accounted for 2.5-7.6-times greater mean HCRU and direct asthma-related costs for each HCRU-related category vs the main active-asthma population. In the US, higher asthma-related costs have also been associated with elevated eosinophil levels. ${ }^{19}$ In our study we found asthma-related costs, for all HCRU categories, were substantially higher (over 2-fold) for the HD ICS SEA and SEA patient populations, vs the general asthma population, but we did not see trends in increasing HCRU and associated costs with increasing eosinophil level within the SEA population, in contrast to other data. ${ }^{17} \mathrm{~A}$ comparison of absolute asthma-related costs is difficult to make between countries due to socioeconomic differences and differences in healthcare systems. However, regarding relative costs, a systematic literature review of economic burden of asthma in 68 studies found hospitalization and medication costs were the most important drivers of direct costs, ${ }^{20}$ while we found OPD costs to be the main driver. In our study, there were limited episodes of asthma-related hospitalization occurring during the 12-month follow-up period (SEA patients had $0.3 \pm 0.14$ days/patient-year of hospitalization due to asthma, as shown in Table 4). This is in-line with our expectation as patients treated at tertiary medical centres are given specialized and intensive care to keep symptoms under control; this was reflected in the greater utilization of OPD services $(4.7 \pm 0.48$ times/patient-year for SEA patients) which resulted in greater healthcare resource use on OPD visits and medication.

Respiratory medication coverage rates were higher for SEA vs general asthma patients by 2 - to 3 -fold; however, adherence to overall respiratory medications was comparable ( 67\%), and higher in HD ICS SEA patients (73.7\%); these values are considered high based on studies examining the compliance rate of asthma patients $(55 \%)^{15}$ and the adherence rate of patients with SA (28-67\%). ${ }^{21}$ Of note, our overall medication adherence for SEA and HD ICS SEA patients based on PDC $\geq$ $80 \%$ was broadly similar to that demonstrated previously for long-term oral and inhaled controller medication in a patient population with SA (58.3\%). ${ }^{22}$ Despite high medication coverage rates, we found approximately half of SEA and HD ICS SEA patients continued to experience exacerbations. Considering the high overall medication adherence results, the likelihood that the asthma of SEA or HD ICS SEA patients in our study would be categorized as difficult-to-treat rather than refractory $^{7}$ due to poor adherence is therefore low. We also assessed comorbidities and modifiable risk factors in the study and found that this was higher in SEA vs. general asthma population. Though SEA patients were more frequently prescribed with SABA vs. general asthma patients (Table 3 ), the rate of PDC was not different between SEA and general asthma patients (Appendix S2). The persistence of exacerbations in these patient populations is therefore more likely indicative of suboptimal disease control with current treatments. As per GINA guidelines for the diagnosis and management of asthma, severe asthma is asthma that is poorly controlled despite being managed with GINA Step 4-5 treatment, good adherence and good inhaler techniques. ${ }^{23}$ As patients in our study fulfilled these criteria, and the majority of the patients had access to inhaler training, we believed most of the patients we recruited had severe asthma rather than difficult-to-treat asthma. 
We found few SEA patients were using omalizumab. A retrospective, population-based cohort study using Taiwan National Health Insurance data also reported low coverage of omalizumab (0.4\% SAA patients in 2011), despite associated reductions in number of asthma medications, exacerbations and ED visits. ${ }^{24}$ In Korean SA patients, omalizumab was found to be used in just $1.8 \%$, although this only represents private use. ${ }^{25}$ Low biologic utilization may be due to healthcare reimbursement factors, ${ }^{25}$ associated costs that may hinder prescription of biologics by physicians, reservation of omalizumab for patients specifically with SAA, or to patients' treatment with multiple non-biologic medications and/or non-evident clinical benefits over contemporary maintenance inhaler treatments. ${ }^{26}$

This is the first study in Taiwan assessing epidemiology and burden of SEA and provides needed real-world, and ethnic data on SEA in an adult, Chinese population. Although clinical databases can be associated with data quality issues and missing variables, the use of the VGHTC research-ready database ${ }^{27}$ may minimize this as it contains a combination of EMR and claims data. Our study has some limitations. Patients with COPD were not excluded, limiting homogeneity of the study population, and patient numbers in the subgroups of SEA patients stratified by BEC were small, limiting comparisons between groups. This research was conducted in a single, though large medical center in Central Taiwan, which could limit external generalizability. However, cost data are expected to be broadly representative of other centers in Taiwan, as prescription patterns and quality of care should be standardized between centers. A further limitation is immortal-time bias, as data for patients who may have died within 12 months after the index date would have been excluded from the study. Lastly, because data from the VGHTC EMR database were not originally collected to answer research questions, misclassification bias can occur.

\section{Conclusion}

Our results indicate an unmet need for effective treatments for patients classified with SEA in Taiwan; these patients account for substantially greater asthma-related HCRU and all-cause medical costs than general asthma patients.

\section{Consent for Publication \\ Not applicable}

\section{Availability of Data and Materials}

GSK makes available anonymized individual participant data and associated documents from interventional clinical studies which evaluate medicines, upon approval of proposals submitted to www.clinicalstudydatarequest.com. To access data for other types of GSK sponsored research, for study documents without patient-level data and for clinical studies not listed, please submit an enquiry via the website.

\section{Competing Interests}

SS and Y-FH are employees of and holds stocks with GlaxoSmithKline; L-WT and T-ML reports no competing interests; Y-HC: reports grant payment and consulting fees or honoraria from GlaxoSmithKline.

\section{Funding}

This study was sponsored by GSK (PRJ2409/208976).

\section{Author Contributions}

Y-HC had full review access to the database population used to create the study population and SS, Y-FH, L-WT and T-ML were provided with the full clinical study report for review as part of this analysis. SS, Y-FH, L-WT, T-ML and Y-HC contributed to the conception, design, execution or analysis, and interpretation of these data. All authors approved the final version to be published after critically revising the manuscript/publication for important intellectual content.

\section{Acknowledgements}

Editorial support in the form of development of the initial draft, collating author comments, editorial suggestions to draft versions of this paper, assembling tables and figures, copyediting and referencing was provided by Ruth Le Fevre, $\mathrm{PhD}$, Costello Medical, Singapore and was funded by GSK. Funding for the study was provided by GlaxoSmithKline (GSK ID PRJ2409/208976)

\section{References}

1. Chung KF, Wenzel SE, Brozek JL, Bush A, Castro M, Sterk PJ, et al. International ERS/ATS guidelines on definition, evaluation and treatment of severe asthma. Eur Respir J. 2014;43(2):343-73.

2. Global Initiative for Asthma [Internet]. Fontana: GINA; c2020 [cited 2020 Mar 2]. Global Strategy for Asthma Management and Prevention, 2018; [about 1 screen]. Available from: https://www.ginasthma.org.

3. Calhoun WJ, Haselkorn T, Mink DR, Miller DP, Dorenbaum A, Zeiger RS. Clinical burden and predictors of asthma exacerbations in patients on guideline-based steps 4-6 asthma therapy in the TENOR cohort. J Allergy Clin Immunol Pract. 2014;2(2):193-200.

4. Accordini S, Corsico AG, Braggion M, Gerbase MW, Gislason D, Gulsvik A, et al. The Cost of Persistent Asthma in Europe: An International Population-Based Study in Adults. Int Arch Allergy Immunol. 2013;160(1): 93-101.

5. Sullivan SD, Rasouliyan L, Russo PA, Kamath T, Chipps BE, Group TS. Extent, patterns, and burden of uncontrolled disease in severe or difficult-to-treat asthma. Allergy. 2007;62(2):126-33.

6. Ivanova JI, Bergman R, Birnbaum HG, Colice GL, Silverman RA, McLaurin K. Effect of asthma exacerbations on health care costs among asthmatic patients with moderate and severe persistent asthma. J Allergy Clin Immunol. 2012;129(5):1229-35.

7. Guilbert TW, Garris C, Jhingran P, Bonafede M, Tomaszewski KJ, Bonus T, et al. Asthma That Is Not Well-Controlled Is Associated with Increased Healthcare Utilization and Decreased Quality of Life. J Asthma. 2011;48(2):126-32.

8. Shaw DE, Sousa AR, Fowler SJ, Fleming LJ, Roberts G, Corfield J, et al. Clinical and inflammatory characteristics of the European U-BIOPRED adult severe asthma cohort. Eur Respir J. 2015;46(5):1308-21.

9. Omachi TA, Iribarren C, Sarkar U, Tolstykh I, Yelin EH, Katz PP, et al. Risk factors for death in adults with severe asthma. Ann Allergy Asthma Immunol. 2008;101(2):130-6.

10. Wagener AH, de Nijs SB, Lutter R, Sousa AR, Weersink EJ, Bel EH, et al. External validation of blood eosinophils, $\mathrm{FE}(\mathrm{NO})$ and serum periostin as surrogates for sputum eosinophils in asthma. Thorax. 2015;70(2):115-20.

11. Zhang XY, Simpson JL, Powell H, Yang IA, Upham JW, Reynolds PN, et al. Full blood count parameters for the detection of asthma inflammatory phenotypes. Clin Exp Allergy. 2014;44(9):1137-45.

12. Albers FC, Mullerova H, Gunsoy NB, Shin JY, Nelsen LM, Bradford ES, et al. Biologic treatment eligibility for real-world patients with severe asthma: The IDEAL study. J Asthma. 2018;55(2):152-60.

13. Global Initiative for Asthma [Internet]. Fontana: GINA; c2020 [cited 2020 Mar 2]. Global Strategy for Asthma Management and Prevention, 2015. Available from:https://www.ginasthma.org. 
14. Kostikas K, Brindicci C, Patalano F. Blood Eosinophils as Biomarkers to Drive Treatment Choices in Asthma and COPD. Curr Drug Targets. 2018;19(16):1882-96.

15. Claxton AJ, Cramer J, Pierce C. A systematic review of the associations between dose regimens and medication compliance. Clin Ther. 2001;23(8): 1296-310.

16. Pharmacy Quality Alliance [Internet]. Alexandria (VA); c2018 [cited 2020 Mar 2]. PQA Adherence Measures, 2018; [about 1 screen]. Available from:https://www.pqaalliance.org/adherence-measures.

17. Kerkhof M, Tran TN, Soriano JB, Golam S, Gibson D, Hillyer EV, et al. Healthcare resource use and costs of severe, uncontrolled eosinophilic asthma in the UK general population. Thorax. 2018;73(2):116-24.

18. Moore WC, Meyers DA, Wenzel SE, Teague WG, Li H, Li X, et al. Identification of asthma phenotypes using cluster analysis in the Severe Asthma Research Program. Am J Respir Crit Care Med. 2010;181(4): 315-23.

19. Casciano J, Krishnan J, Dotiwala Z, Li C, Sun SX. Clinical and Economic Burden of Elevated Blood Eosinophils in Patients With and Without Uncontrolled Asthma. J Manag Care Spec Pharm. 2017;23(1):85-91.

20. Bahadori K, Doyle-Waters MM, Marra C, Lynd L, Alasaly K, Swiston J, et al. Economic burden of asthma: a systematic review. BMC Pulm Med. 2009;9:24.

21. Boutopoulou B, Koumpagioti D, Matziou V, Priftis KN, Douros K. Interventions on Adherence to Treatment in Children With Severe Asthma: A Systematic Review. Front Pediatr. 2018;6:232.

22. Chastek B, Korrer S, Nagar SP, Albers F, Yancey S, Ortega H, et al. Economic Burden of Illness Among Patients with Severe Asthma in a Managed Care Setting. J Manag Care Spec Pharm. 2016;22(7):848-61.

23. Global Initiative for Asthma [Internet]. Fontana: GINA; c2020 [cited 2020 Jun 22]. Diffucult-to-Treat \& Severe Asthma in adolescent and adult patients Diagnosis and Management and Prevention, 2018. Available from:https://www.ginasthma.org.

24. Chen HC, Huang CD, Chang E, Kuo HP. Efficacy of omalizumab $($ Xolair $(\mathrm{R}))$ in patients with moderate to severe predominately chronic oral steroid dependent asthma in Taiwan: a retrospective, populationbased database cohort study. BMC Pulm Med. 2016;16:3.

25. Kim MH, Kim SH, Park SY, Ban GY, Kim JH, Jung JW, et al. Characteristics of Adult Severe Refractory Asthma in Korea Analyzed From the Severe Asthma Registry. Allergy Asthma Immunol Res. 2019; 11(1):43-54

26. Tadrous M, Khuu W, Lebovic G, Stanbrook MB, Martins D, Paterson JM, et al. Real-world health care utilization and effectiveness of omalizumab for the treatment of severe asthma. Ann Allergy Asthma Immunol. 2018;120(1):59-65 e2.

27. Yang U-C, Hsiao T-H, Lin C-H, Lee W-J, Y-S. L, Fann Y, C. Integrative LHS for precision medicine research: A shared NIH and Taiwan CIMS experience. Learn Health Syst. 2018;e10071.

\section{Appendix S1}

\section{Supplementary Methods}

\section{Taichung Veterans General Hospital (VGHTC)}

The VGHTC EMR database captures patients' demographic, prescription, hospital admissions and referrals information, and prescription- and patient-level costs (inclusive of self-pay and reimbursement claims to the National Health Insurance) on all patients seen in the VGHTC healthcare system since 2009. The VGHTC network includes four hospitals (VGHTC, Chiayi Branch, Puli Branch, Wanqiao branch) that provide a standardized quality of care across sites in different geographical locations spanning the entire district in central Taiwan. The EMR data from the hospitals reside on a shared database - the Clinical Information Research \& Development Center (CIDC) shared database platform.

\section{Patient Inclusion Criteria ICD-9 codes of asthma and comorbidities of interest}

The International Classification of Diseases (ICD) codes used in the identification of asthma and comorbidities of interest are listed in the table below.

Table S1. ICD-9 codes of asthma and comorbidities of interest

Comorbidities of Interest

Asthma

Nasal polyps

Rhinitis allergic

Rhinitis chronic

Cardiac Disorders

Tachycardia, dysrhythmias

\section{Atrial fibrillation}

Cardiac dysrhythmias (Other specified and unspecified) - includes bradycardia

Myocardial infarction

Angina pectoris

Unstable angina

Transient ischemic attack

Other forms of chronic ischemic heart disease

Cardiac failure congestive (congestive heart failure)

Atrioventricular block

Bundle branch block right

Conduction disorder (excludes atrioventricular block and bundle branch block right)

\section{Palpitations}

Pericardial effusion

Ventricular extra-systoles

\section{ICD-9 codes}

493.00, 493.01, 493.02, 493.10, 493.11, 493.12, 493.90, 493.91 (ICD-10 codes: J45, J46)

$471.0,471.9$

$477,477.0,477.1,477.2,477.8,477.9$

$472,472.0,472.1,472.2$

427.0, 427.1, 427.2, 427.6 (427.60, 427.61, 427.69)

$427.3(427.31,427.32)$

$427.8(427.81,427.89), 427.9$

410 (410.0, 410.00, 410.01, 410.02, $410.1,410.10,410.11,410.12,410.2$, 410.20, 410.21, 410.22, 410.3, 410.30, 410.31, 410.32, 410.4, 410.40, 410.41, $410.42,410.5,410.50,410.51,410.52$, 410.6, 410.60, 410.61, 410.62, 410.7, 410.70, 410.71, 410.72, 410.8, 410.80, 410.81, 410.82, 410.9, 410.90, 410.91, 410.92) 411 (411.0, 411.1, 411.8, 411.81, 411.89)

413 (413.0, 413.1, 413.9)

411.1

V12.54

414 (414.0, 414.00, 414.01, 414.02, 414.03, 414.04, 414.05, 414.06, 414.07, 414.1, 414.10, 414.11, 414.12, 414.19, 414.8, 414.9)

$428(428.0,428.1428 .2,428.20,428.21$, 428.22, 428.23,428.3, 428.30, 428.31, 428.32, 428.33, 428.4, 428.40, 428.41, 428.42, 428.43,428.9

$426.1(426.10,426.11,426.12,426.13)$

426.4

426 (426.0, 426.2, 426.3, 426.5, 426.50, $426.51,426.52,426.53,426.54,426.6$, $426.7,426.8,426.81,426.82,426.89$. 426.9)

785.1

420

$427.60,427.69$ 
Table S1. (Continued)

\begin{tabular}{|c|c|}
\hline Comorbidities of Interest & ICD-9 codes \\
\hline Hypertension & $\begin{array}{l}401(401.0,401.1,401.9) \\
402(402.0,402.00,402.01,402.1, \\
402.10,402.11,402.9,402.90,402.91) \\
403(403.0,403.00,403.01,403.1, \\
403.10,403.11,403.9,403.90,403.91) \\
404(404.0,404.00,404.01,404.02, \\
404.03,404.1,404.10,404.11,404.12, \\
404.13,404.9,404.90,404.91,404.92, \\
404.93) \\
405(405.0,405.01,405.09,405.1, \\
405.11,405.19,405.9,405.91,405.99)\end{array}$ \\
\hline Pulmonary hypertension & $416.0,416.8$ \\
\hline $\begin{array}{l}\text { Cerebrovascular disorders (that } \\
\text { is not stroke) }\end{array}$ & $\begin{array}{l}780.3,780.31,780.32,780.39 \text { (Seizures/ } \\
\text { convulsions (non-epileptic) } \\
436,437,438\end{array}$ \\
\hline Ischemic stroke & $\begin{array}{l}433(433.0,433.00,433.01,433.1, \\
433.10,433.11,433.2,433.20, \\
433.21,433.3,433.30,433.31,433.8, \\
433.80,433.81,433.9,433.90,433.91) \\
434(434.0,434.00,434.01,434.1, \\
434.10,434.11,434.9,434.90,434.91) \\
437.1\end{array}$ \\
\hline Hemorrhagic stroke & $430,431,432,432.0,432.1,432.9$ \\
\hline Pulmonary embolism & $\begin{array}{l}\text { Pulmonary embolism: } 415.1,415.19 \\
\text { Deep vein thrombosis (upper and lower } \\
\text { extremities): } 451.1(451.11,451.19) \text {, } \\
451.2,451.81,451.83,451.84,453.1, \\
453.2,453.4(453.40,453.41,453.42), \\
453.8,453.9 \\
\text { Portal vein thrombosis: } 452 \\
\text { Other thromboembolic events: } 362.35 \text {, } \\
\text { 362.36, } 437.6,451.0,451.82,451.89 \text {, } \\
451.9,453.0,453.2,453.3\end{array}$ \\
\hline Hypotension & $\begin{array}{l}458(458.0,458.1,458.2,458.21,458.29 \\
458.8,458.9)\end{array}$ \\
\hline Thrombophlebitis & 999.2 \\
\hline
\end{tabular}

\section{SEA patients}

Criteria for GINA step 4 or 5 treatment were as follows: Step 4 - Add on tiotropium or a leukotriene receptor antagonist (LTRA) and/or sustained release theophylline to any of the GINA Step 3 treatments ([a] low-dose ICS plus LABA in a single device, [b] low-dose ICS plus LABA in multiple devices, [c] medium- or HD ICS, [d] low-dose ICS plus LTRA, or [e] low-dose ICS plus sustained-release theophylline) or combinations (to be considered as a treatment combination each medicine must have been prescribed within a 30-day window, the rule on medication combinations did not apply where ICS and LABA were administered in one inhaler), or were given medium- or high-dose (HD) ICS plus LABA in either a single device or in multiple devices; Step 5 - Patients who had also been given systemic steroids (i.e., oral corticosteroids [OCS]) or anti-IgE treatment (e.g., omalizumab [Xolair]) in addition to the GINA Step 4 treatment combinations.

Exacerbations were defined as use of OCS burst for asthma symptoms, asthma-related emergency department (ED) visit, or hospitalization.

\section{HD ICS patients}

An additional subgroup of patients, who had received HD ICS, was also extracted and analyzed, as in clinical practice, these patients may be considered for treatment with biologics (according to Step 5 GINA 2015: OCS or anti-IgE treatment in addition to Step 4 treatment) if they have maximized their choices of combination therapies and doses and have persistent symptoms despite optimized treatment with high dose controller medications and treatment of modifiable risk factors).

\section{SEA Subpopulations}

Patients with SEA were classified into the following four subpopulations to better characterise the patients eligible for treatment with biologics.

Table S2. Classification criteria for SEA subpopulations

Population 1 Population 2

Population 3

Population 4

OR $\geq 150$ cells $/ \mu \mathrm{L}$ measured on

index date

A history of $\geq 2$ exacerbations in the 12 months prior to index date

OR

Continuous OCS (5 mg per day) use

for 6 months prior to index date
A history of $\geq 2$ exacerbations in the 12 months prior to index date OR

Continuous OCS ( $5 \mathrm{mg}$ per day) use for 6 months prior to index date
A history of $\geq 4$ exacerbations in the 12 months prior to index date OR

Continuous OCS (5 mg per day) use for 6 months prior to index date
A history of $\geq 4$ exacerbations in the 12 months prior to index date, with $\geq 1$ exacerbation recorded as $\mathrm{ED}$ or hospitalization AND

Continuous OCS (5 mg per day) use for 6 months prior to index date

Continuous OCS use was defined as follows: OCS1: A sequence of prednisolone claims that occurred $\leq 7$ days between prescriptions (based on the prescription pattern in the local context - the clinic revisit interval is usually 7 days apart) OR OCS2: In the observational period, those with total prednisolone prescription $\geq$ $900 \mathrm{mg}$ within 180 days post index (time varying covariates were ignored and the total prescribed dose of prednisolone of $5 \mathrm{mg} / \mathrm{day}$ for $180 \mathrm{days}$ [ $\geq 900 \mathrm{mg}$ ] were counted) OR OCS3: Included OCS1 and OCS2.

Exacerbations were defined as above (see Patient Inclusion Criteria, SEA Patients). 
The proportion of patients in each subpopulation was assessed for those with: 6-months continuous OCS use, BEC $\geq 150$ cells $/ \mu \mathrm{L}$ measured on index date, $\mathrm{BEC} \geq 300$ cells $/ \mu \mathrm{L}$ captured in the 12 months prior to index date and number of exacerbations $(2+/ 3+/ 4+/ 5+)$.

\section{Demographics and clinical characteristics}

Age, gender, body-mass index (BMI), smoking status, comorbidities, atopy status (scored 'Yes' if total $\mathrm{IgE}>100 \mathrm{IU} / \mathrm{mL}$ or any of allergen-specific $\operatorname{IgE}>0.35 \mathrm{KU} / \mathrm{mL}$ or if any multiple allergen-specific IgE screen was positive), ${ }^{1,2}$ total $\operatorname{IgE}$ and $\mathrm{BEC}$ were described. BEC were described as the mean value over the 12-month follow-up period.

\section{Exacerbations}

An asthma-related ED visit was any record for an ED visit related to an asthma diagnosis code. An asthma-related hospital admission was any asthma-related referral or hospitalization with a discharge diagnosis of asthma. OCS-defined exacerbations were any OCS prescription with an asthma medical code recorded within \pm 2 weeks. Systemic steroids administered via injections were not included in the ascertainment of OCS-defined exacerbations as intravenous steroids were captured via hospitalization-related exacerbations.

\section{Medication Use}

Medication records in the database were encoded according to National Health Insurance drug codes. Asthma medications analysed in this study included: long-acting muscarinic agonists (LAMA), LABA, ICS, short-acting $\beta 2$-agonists (SABA), theophylline, LTRA, systemic corticosteroids, systemic $\beta$ agonists, omalizumab (Xolair), tiotropium, ICS+LABA (free-dose), ICS+theophylline (free-dose), ICS+LTRA (free-dose), LABA+LAMA (fixed-dose), SABA+short-acting muscarinic antagonists (SAMA) (fixed-dose), and ICS+LABA (fixed-dose).

\section{Medication adherence}

Assessment of medication adherence using proportion of days covered (PDC) started with the first claim for controller therapy; PDC was calculated as the ratio of medication covered days to duration of the medication treatment period (number of days).

\section{OCS average daily dose}

For multiple OCS claims to be considered part of the same episode, they must have had the same strength/dose; otherwise, OCS claims were considered as independent OCS episodes. This applied to OCS claims that occurred on the same date as well as those that occurred during a prior OCS treatment period. The average daily dose of OCS was calculated using prednisone equivalent doses.

\section{All-cause and asthma-related healthcare costs}

For asthma-related costs, all healthcare use encompassed medical claims with an asthma diagnosis in the primary position. All-cause costs were those irrespective of asthma diagnosis. For each category, total cost, and medication costs were reported. Total cost was the sum of all medical fees; medication costs included drug costs and any administration/infusion fees submitted on the same medical claim. The following healthcare costs were presented in this study for the 12-month follow-up period: 1) cost of hospitalization, 2) cost of OPD visits, and 3) cost of ED visits. Costs were standardized to the most recent year of data availability in Taiwan.

\section{Bootstrapping procedure}

The following algorithm was used in the bootstrapping method for cost calculation:

1. A sample of $n$ patients (the same number as the study population) was drawn with replacement from the study population and the cost difference was calculated based on this sample using the linear model.

2. The sampling (i.e., step 1) was repeated and the cost difference calculated between exposure groups $\times$ times. In this study, 999 replications were used to carry out hypothesis testing.

3. The $999+1$ (the original sample estimate) cost difference estimates were ordered from the lowest to the highest observed values.

4. The $95 \%$ CI was identified based on the 2.5 and 97.5 percentiles of the ranked values. The $p$-value was calculated from the observed empirical distribution.

\section{Appendix S2}

\section{Supplementary Results: BEC Subgroups}

Baseline patient demographics and clinical characteristics

Patient numbers for the various pre-specified BEC subgroups were small ( $n=29-59$ for the $<150$ cells $/ \mu \mathrm{L}$ cut-off and $>400$ cells $/ \mu \mathrm{L}$ cut-off groups, respectively), limiting the comparison of results between groups. However, the results for these subgroups were generally similar to the HD ICS SEA or overall SEA populations. The $<150$ cells/ $\mu \mathrm{L}$ subgroup was oldest, had fewest female patients, highest BMI, lowest atopy and the greatest patient proportion with $\operatorname{IgE} \leq 30 \mathrm{IU} / \mathrm{mL}$ (Table 1).

\section{Exacerbations}

All eosinophil level subgroups of the SEA population had higher mean exacerbations (ranging from $1.2 \pm 1.77$ in the $>300-400$ cells $/ \mu \mathrm{L}$ group to $1.9 \pm 3.96$ in the $>400$ cells $/ \mu \mathrm{L}$ group) compared with the general asthma population. Numerically greater proportions of patients in each eosinophil-level subgroup of the SEA population experienced each category of exacerbations vs the general asthma patients. Number of ED visits or hospitalizations following exacerbations were generally similar to that for the SEA and HD ICS patients, although there was some variation between groups (Table 2).

\section{Healthcare resource use and costs}

There was variation in asthma-related HCRU in the different eosinophil subgroups but it was generally similar to that of the SEA or HD ICS SEA populations and greater than the general asthma population (Table 4). 


\section{Asthma-related and all-cause costs}

Each of the eosinophil-level subgroups in the SEA incurred higher asthma-related costs vs general asthma patients; this result was most pronounced for the lowest and highest subgroups for OPD costs, medication costs, and total costs (Figure 2B). There was variation in all-cause costs between the different eosinophil subgroups for all healthcare categories; all subgroups incurred greater costs for all categories vs the general asthma population and the greatest all-cause costs for all healthcare categories except hospitalization costs were incurred by the 150-300 cells/ $\mu \mathrm{L}$ subgroup (Figure 3B).

Use of SABA in SEA and general asthma patients

The rate of PDC were comparable between SEA and general asthma patients.
Table S3. PDC of SABA in SEA and general asthma patients

\begin{tabular}{lccc} 
& $\begin{array}{c}\text { General asthma } \\
(\mathrm{N}=2439)\end{array}$ & $\begin{array}{c}\text { All SEA } \\
(\mathbf{N}=\mathbf{1 6 2})\end{array}$ & P-value \\
\hline $\mathrm{PDC}(\%)$, mean \pm SD & $33.7 \pm 32.75$ & $28.5 \pm 32.64$ & 0.18 \\
\hline
\end{tabular}

Figure S1. Study Timeline

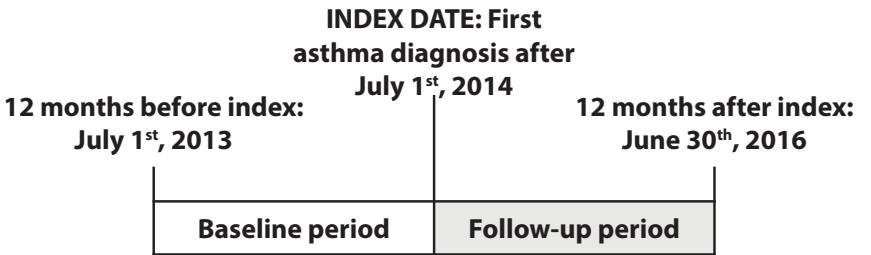

Supplementary Results: SEA subpopulations classified based on exacerbations and OCS use Table S4. Clinical characteristics and OCS utilisation in SEA subpopulations at 3 months and 6 months during the follow-up period

\begin{tabular}{|c|c|c|c|c|c|c|c|c|}
\hline \multirow[b]{2}{*}{ OCS1 } & \multicolumn{2}{|c|}{ Population 1} & \multicolumn{2}{|c|}{ Population 2} & \multicolumn{2}{|c|}{ Population 3} & \multicolumn{2}{|c|}{ Population 4} \\
\hline & $\begin{array}{c}3 \mathrm{M} \\
\mathrm{N}=80\end{array}$ & $\begin{array}{c}6 \mathrm{M} \\
N=80\end{array}$ & $\begin{array}{c}3 \mathrm{M} \\
\mathrm{N}=70\end{array}$ & $\begin{array}{c}6 M \\
N=70\end{array}$ & $\begin{array}{c}3 \mathrm{M} \\
\mathrm{N}=43\end{array}$ & $\begin{array}{c}6 M \\
N=43\end{array}$ & $\begin{array}{c}3 \mathrm{M} \\
\mathrm{N}=1\end{array}$ & $\begin{array}{c}6 \mathrm{M} \\
\mathrm{N}=0\end{array}$ \\
\hline 6 months continuous OCS & $5(6.3)$ & $3(3.8)$ & $4(5.7)$ & $2(2.9)$ & $4(9.3)$ & $2(4.7)$ & $1(100.0)$ & $0(0.0)$ \\
\hline $\mathrm{BEC} \geq 150$ cells $/ \mu \mathrm{L}$ (index date) & $20(25.0)$ & $20(25.0)$ & $10(14.3)$ & $10(14.3)$ & $7(16.3)$ & $7(16.3)$ & $0(0.0)$ & $0(0.0)$ \\
\hline $\begin{array}{l}\mathrm{BEC} \geq 300 \text { cells } / \mu \mathrm{L} \text { (past } 12 \\
\text { months) }\end{array}$ & $70(87.5)$ & $70(87.5)$ & $70(100.0)$ & $70(100.0)$ & $43(100.0)$ & $43(100.0)$ & $1(100.0)$ & $0(0.0)$ \\
\hline No exacerbation & $0(0.0)$ & $0(0.0)$ & $0(0.0)$ & $0(0.0)$ & $0(0.0)$ & $0(0.0)$ & $0(0.0)$ & $0(0.0)$ \\
\hline 1 exacerbation & $0(0.0)$ & $0(0.0)$ & $0(0.0)$ & $0(0.0)$ & $0(0.0)$ & $0(0.0)$ & $0(0.0)$ & $0(0.0)$ \\
\hline 2 exacerbation & $19(23.8)$ & $19(23.8)$ & $16(22.9)$ & $16(22.9)$ & $0(0.0)$ & $0(0.0)$ & $0(0.0)$ & $0(0.0)$ \\
\hline 3 exacerbation & $13(16.3)$ & $13(16.3)$ & $11(15.7)$ & $11(15.7)$ & $0(0.0)$ & $0(0.0)$ & $0(0.0)$ & $0(0.0)$ \\
\hline 4 exacerbation & $10(12.5)$ & $10(12.5)$ & $10(14.3)$ & $10(14.3)$ & $10(23.3)$ & $10(23.3)$ & $0(0.0)$ & $0(0.0)$ \\
\hline$\geq 5$ exacerbation & $38(47.5)$ & $38(47.5)$ & $33(47.1)$ & $33(47.1)$ & $33(76.7)$ & $33(76.7)$ & $1(100.0)$ & $0(0.0)$ \\
\hline OCS2 & $\begin{array}{c}3 \mathrm{M} \\
\mathrm{N}=83\end{array}$ & $\begin{array}{c}6 \mathrm{M} \\
\mathrm{N}=83\end{array}$ & $\begin{array}{c}3 \mathbf{M} \\
\mathbf{N}=73\end{array}$ & $\begin{array}{c}6 \mathrm{M} \\
\mathrm{N}=73\end{array}$ & $\begin{array}{c}3 \mathrm{M} \\
\mathrm{N}=47\end{array}$ & $\begin{array}{c}6 \mathrm{M} \\
\mathrm{N}=47\end{array}$ & $\begin{array}{c}3 \mathbf{M} \\
\mathbf{N}=2\end{array}$ & $\begin{array}{c}6 \mathrm{M} \\
\mathrm{N}=0\end{array}$ \\
\hline 6 months continuous OCS & $5(6.0)$ & $3(3.6)$ & $4(5.5)$ & $2(2.7)$ & $4(8.5)$ & $2(4.3)$ & $1(50.0)$ & $0(0.0)$ \\
\hline $\mathrm{BEC} \geq 150$ cells $/ \mu \mathrm{L}$ (index date) & $20(24.1)$ & $20(24.1)$ & $10(13.7)$ & $10(13.7)$ & $8(17.0)$ & $8(17.0)$ & $0(0.0)$ & $0(0.0)$ \\
\hline $\begin{array}{l}\mathrm{BEC} \geq 300 \text { cells } / \mu \mathrm{L} \text { (past } 12 \\
\text { months) }\end{array}$ & $73(88.0)$ & $73(88.0)$ & $73(100.0)$ & $73(100.0)$ & $47(100.0)$ & $47(100.0)$ & $2(100.0)$ & $2(100.0)$ \\
\hline No exacerbation & $3(3.6)$ & $3(3.6)$ & $3(4.1)$ & $3(4.1)$ & $3(6.4)$ & $3(6.4)$ & $0(0.0)$ & $0(0.0)$ \\
\hline 1 exacerbation & $0(0.0)$ & $0(0.0)$ & $0(0.0)$ & $0(0.0)$ & $0(0.0)$ & $0(0.0)$ & $0(0.0)$ & $0(0.0)$ \\
\hline 2 exacerbation & $19(22.9)$ & $19(22.9)$ & $16(21.9)$ & $16(21.9)$ & $1(2.1)$ & $1(2.1)$ & $0(0.0)$ & $0(0.0)$ \\
\hline 3 exacerbation & $13(15.7)$ & $13(15.7)$ & $11(15.1)$ & $11(15.1)$ & $0(0.0)$ & $0(0.0)$ & $0(0.0)$ & $0(0.0)$ \\
\hline 4 exacerbation & $10(12.0)$ & $10(12.0)$ & $10(13.7)$ & $10(13.7)$ & $10(21.3)$ & $10(21.3)$ & $0(0.0)$ & $0(0.0)$ \\
\hline$\geq 5$ exacerbation & $38(45.8)$ & $38(45.8)$ & $33(45.2)$ & $33(45.2)$ & $33(70.2)$ & $33(70.2)$ & $2(100.0)$ & $2(100.0)$ \\
\hline
\end{tabular}


Table S4. (Continued)

\begin{tabular}{|c|c|c|c|c|c|c|c|c|}
\hline \multirow[b]{2}{*}{ OCS3 } & \multicolumn{2}{|c|}{ Population 1} & \multicolumn{2}{|c|}{ Population 2} & \multicolumn{2}{|c|}{ Population 3} & \multicolumn{2}{|c|}{ Population 4} \\
\hline & $\begin{array}{c}3 \mathrm{M} \\
\mathrm{N}=\mathbf{8 0}\end{array}$ & $\begin{array}{c}6 \mathrm{M} \\
N=80\end{array}$ & $\begin{array}{c}3 \mathrm{M} \\
\mathrm{N}=70\end{array}$ & $\begin{array}{c}6 M \\
N=70\end{array}$ & $\begin{array}{c}3 M \\
N=43\end{array}$ & $\begin{array}{c}6 M \\
N=43\end{array}$ & $\begin{array}{c}3 \mathrm{M} \\
\mathbf{N}=1\end{array}$ & $\begin{array}{c}6 \mathrm{M} \\
\mathrm{N}=\mathbf{0}\end{array}$ \\
\hline 6 months continuous OCS & $5(6.3)$ & $3(3.8)$ & $4(5.7)$ & $2(2.9)$ & $4(9.3)$ & $2(4.7)$ & $1(100.0)$ & $0(0.0)$ \\
\hline $\mathrm{BEC} \geq 150$ cells $/ \mu \mathrm{L}$ (index date) & $20(25.0)$ & $20(25.0)$ & $10(14.3)$ & $10(14.3)$ & $7(16.3)$ & $7(16.3)$ & $0(0.0)$ & $0(0.0)$ \\
\hline $\begin{array}{l}\mathrm{BEC} \geq 300 \text { cells } / \mu \mathrm{L} \text { (past } 12 \\
\text { months) }\end{array}$ & $70(87.5)$ & $70(87.5)$ & $70(100)$ & $70(100)$ & $43(100.0)$ & $43(100.0)$ & $1(100.0)$ & $0(0.0)$ \\
\hline No exacerbation & $0(0.0)$ & $0(0.0)$ & $0(0.0)$ & $0(0.0)$ & $0(0.0)$ & $0(0.0)$ & $0(0.0)$ & $0(0.0)$ \\
\hline 1 exacerbation & $0(0.0)$ & $0(0.0)$ & $0(0.0)$ & $0(0.0)$ & $0(0.0)$ & $0(0.0)$ & $0(0.0)$ & $0(0.0)$ \\
\hline 2 exacerbation & $19(23.8)$ & $19(23.8)$ & $16(22.9)$ & $16(22.9)$ & $0(0.0)$ & $0(0.0)$ & $0(0.0)$ & $0(0.0)$ \\
\hline 3 exacerbation & $13(16.3)$ & $13(16.3)$ & $11(15.7)$ & $11(15.7)$ & $0(0.0)$ & $0(0.0)$ & $0(0.0)$ & $0(0.0)$ \\
\hline 4 exacerbation & $10(12.5)$ & $10(12.5)$ & $10(14.3)$ & $10(14.3)$ & $10(23.3)$ & $10(23.3)$ & $0(0.0)$ & $0(0.0)$ \\
\hline$\geq 5$ exacerbation & $38(47.5)$ & $38(47.5)$ & $33(47.1)$ & $33(47.1)$ & $33(76.7)$ & $33(76.7)$ & $1(100.0)$ & $0(0.0)$ \\
\hline
\end{tabular}

BEC, blood eosinophil count; ED, emergency department; OCS, oral corticosteroid; SEA, severe eosinophilic asthma.

1. Chang ML, Cui C, Liu YH, Pei LC, Shao B. Analysis of total immunoglobulin E and specific immunoglobulin E of 3,721 patients with allergic disease. Biomed Rep 2015;3(4):573-7.

2. Johansson SG, Bieber T, Dahl R, Friedmann PS, Lanier BQ, Lockey RF, et al. Revised nomenclature for allergy for global use: Report of the Nomenclature Review Committee of the World Allergy Organization, October 2003. J Allergy Clin Immunol 2004;113(5):832-6. 